\title{
Balloon-assisted transarterial embolization of type 1 spinal dural arteriovenous fistula
}

\author{
Brian Lee, M.D., Ph.D., Vivek A. Mehta, M.D., William J. Mack, M.D., \\ Matthew S. Tenser, M.D., and Arun P. Amar, M.D.
}

Department of Neurosurgery, University of Southern California, Los Angeles

Type 1 spinal dural arteriovenous fistula (dAVF) constitute the vast majority of all spinal vascular malformations. Here we present the case of a 71-year-old male with progressive myelopathy, lower-extremity weakness and numbness, and urinary incontinence. MRI imaging of the thoracic spine demonstrated cord edema, and catheter spinal angiography confirmed a type 1 spinal dAVF. The fistula was supplied by small dural branches of the left L-2 segmental artery. Angiographic cure was achieved with a one-stage procedure in which coils were used to occlude the distal segmental vessels, followed by balloon-assisted embolization with Onyx.

The video can be found here: http://youtu.be/8aehJbueH0U.

(http://thejns.org/doi/abs/10.3171/2014.V2.FOCUS14175)

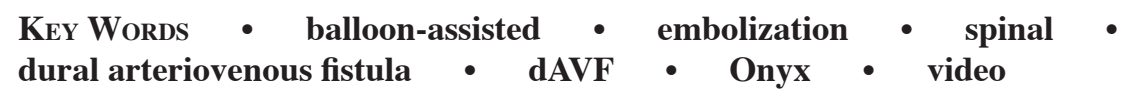

Manuscript submitted May 1, 2014.

Accepted May 27, 2014.

Please include this information when citing this paper: DOI:

10.3171/2014.V2.FOCUS14175.

Address correspondence to: Dr. Brian Lee, University of Southern California, Neurosurgery, 1200 N State Street, Suite 3300, Los Angeles, California 90033. email: brianlee@usc.edu. 